\title{
Comemoração do centenário da descoberta do Schistosoma mansoni no Brasil
}

\begin{abstract}
No remoto dia 27 de julho de 1908, a Revista Científica Brazil Médico publicou um artigo de autoria de Manuel Augusto Pirajá da Silva, sobre a presença de pacientes com esquistossomose no Brasil. Embora a doença nunca tivesse sido encontrada no país, a notícia era de se esperar, pois em 1902 a parasitose já havia sido assinalada por Mauren em Antigua, por Letulle em 1903, em Martinica e por Gonzalez-Martinez em 1904, em Porto Rico. A exemplo do que já havia acontecido com outras doenças, devido ao grande comércio entre África e Brasil, inclusive intenso tráfico de escravos, no sentido da África para a América, haveria muita probabilidade de, algum dia, ocorrer a importação da esquistossomose pelo Brasil.
\end{abstract}

Aluízio Prata ${ }^{1}$
A época coincidia com grandes avanços no estudo das doenças tropicais. A causa de moléstias tradicionais, tidas como de origem desconhecida, como peste, cólera, malária, calazar, sífilis, tuberculose e muitas outras estava sendo esclarecida. Era 0 advento da época pasteuriana. Acompanhada do ocaso da teoria dos miasmas, e da geração espontânea, que veio junto de espetaculares progressos na terapêutica específica das doenças, nas vacinas e no diagnóstico imunológico. Entidades, como a clorose do Egito, a anemia dos trabalhadores em minas ou túneis, a opilação do Brasil, que constituíam problemas de difícil solução foram elucidadas, ao se comprovar serem causadas por anemia, provocada pelos ancilostomídeos que se localizavam no intestino delgado.

Para estudar os variados tipos de vermes, o jovem Bilharz deixou Friburgo, na Alemanha, para acompanhar o seu antigo

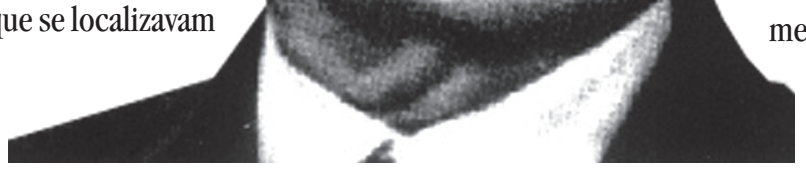

Manuel Augusto Pirajá da Silva hemorragias, infiltrações celulares, edemas, papilomas, principalmente na bexiga, uretra, bacinete e vesícula seminal. No meio das lesões encontrou grande número de ovos e os descreveu muito bem. Alguns tinham espículo terminal e outros, lateral. Ao novo verme, introduzido no sistema helmintológico, Bilharz deu uma denominação de origem latina, chamando-o de Distomum, por possuir duas ventosas, haematobium, pelo habitat sangüíneo e a doença distomíase. Posteriormente, Von Siebold e Meckel Von Hemsbach propuseram a denominação Bilharzia. Por fim, prevaleceu o nome genérico de origem grega Schistosoma, sugerido por Weinland, em 1858, por causa da fenda no corpo do verme macho, onde se aloja a fêmea. Decisão da International Commission on Zoological Nomenclature, Opinião 226, suplementar à Opinião 77.

Harley não encontrando vermes eliminando ovos com espículo lateral na África do Sul, pensou ser o helminto encontrado neste país diferente do existente no Egito e chamou-o Distoma capense. Também Sonsino, de certa feita, interrogou se o verme eliminando ovos com espículo lateral não seria de espécie diferente.

Pirajá examinando fezes, em 1904, no laboratório do Hospital Santa Izabel, deparou com ovos com espículo lateral, mas não soube 0 real significado do achado. Em 1908, voltou a encontrar os mesmos ovos, agora já classificados alhures como Schistosomum. Tais ovos tinham espículo terminal e estes, de agora, tinham espículo lateral. Primeiro encontrou um verme, na segunda necrópsia que Professor Griesinger. Por sugestão de Von Siebold, ele se dedicou ao estudo dos helmintos.

Realizava duas a três necrópsias por dia no Hospital Kasr El Aini. No Cairo, o Doutor Theodore Bilharz fez observações fundamentais e, certamente, a maior delas, foi o descobrimento, em 1851, de um trematódio de sexos separados. Este verme estava associado a extensas lesões nos intestinos, causando disenteria. No aparelho urinário, era o responsável por calcificações,

1. Professor de Medicina Tropical da Universidade Federal do Triângulo Mineiro. fez, outro e na terceira, isolou 24 vermes, sendo dois casais em cópula. Todos na veia porta.

Assim, o descobrimento da esquistossomose no Brasil celebrou seu jubileu de ouro em 1958. Houve sessão solene, distribuição de medalhas comemorativas e emissão de selos. 0 episódio deve ser considerado sob dois aspectos, sendo um deles do ponto de vista de Saúde Pública, pela descoberta no país de uma endemia grave como é a esquistossomose. Na época talvez não tivéssemos meios de avaliar suas proporções. Mas, pouco depois, os exames anatomopatológicos, começaram a definir a magnitude do problema. Já na década de 1920, as observações de Heraldo Maciel, realizadas em marinheiros, revelaram a rapidez com que 
a endemia havia se alastrado. Porém, a quantificação do problema somente ocorreu em 1950, com o inquérito coprológico nacional em escolares, realizado na Divisão de Organização Sanitária, por Barca e Pellon. Calculou-se que na época, já havia cerca de dois milhões e meio de exames de fezes positivos para ovos de Schistosoma mansoni no Brasil. Para 1960, a estimativa era de, pelo menos, seis milhões de esquistossomóticos no país.

0 outro aspecto da descoberta é o científico e está relacionado ao reconhecimento de uma nova espécie de Schistosoma. É exatamente neste sentido que as cuidadosas pesquisas de Pirajá da Silva foram fundamentais. Quando Bilharz fez referência aos dois tipos de ovos, diferenciados pela posição do espículo, embora achasse o fato estranho, ele considerou ambos como pertencentes a mesma espécie e esse engano perdurou por mais de meio século. Arthur Looss na ocasião era Professor de Biologia e Parasitologia da Escola de Medicina do Cairo, onde uma cátedra fora criada especialmente para ele. Looss era considerado o maior helmintologista vivo. Famoso por vários motivos, principalmente por ter elucidado todo o ciclo evolutivo e o modo de transmissão do Ancylostoma duodenale. Quanto à esquistossomose, ele participou ativamente da polêmica. Achava que havia somente uma espécie de Schistosoma e que os ovos com espículo lateral eram não fecundados. 0 debate tornou-se acirrado depois que Sambon propôs que pertenciam à outra espécie de verme, para o qual sugeriu, em homenagem a Manson, o nome de Schistosoma mansoni. Dizia Sambon que a diferença não era somente pelo espículo, mas também porque os ovos com espículo lateral eram encontrados nas fezes e os com espículo terminal, na urina. Havendo ainda diferenças geográficas. Posteriormente, Looss mudou sua interpretação sobre os ovos com espículo lateral, considerando-os como ovos partenogenéticos. Depois, julgou que eles eram o resultado de torção no ootipo, mudando a posição do espículo que de terminal passaria a ventral. No entanto, Fritsch em 1888, já mostrara que havia alteração anatômica no oviduto dos esquistossomas, entrando no ootipo lateralmente nos casos de produção de ovos com espículo lateral e terminalmente quando o espículo era terminal. Não se encontravam os dois tipos de ovos, juntos, no útero da mesma fêmea. Todas essas observações eram importantes, mas não decidiam a questão. Pirajá da Silva aprofundou suas observações com o material obtido na Bahia, publicando seus trabalhos entre 1908 e 1916. Na verdade, até a publicação dos seus trabalhos, não se sabia como separar 0 Schistosoma haematobium do mansoni. Pirajá da Silva mostrou que além dos ovos, outras características diferenciais seriam o número de massas testiculares, quase o dobro no mansoni, e também o ovário situado na metade anterior do corpo, curta dimensão do útero e extensa distribuição das glândulas vitelogênicas nos dois terços posteriores do corpo nas fêmeas. Na época, Pirajá da Silva, cauteloso como fazia habitualmente, consultou sobre os seus achados Patrick Manson, Leiper, Blanchard, Letulle, Le Dantec, Henry, Lortet e Rocha Lima.

Pirajá também descreveu a cercaria blanchardi, isolada do Planorbis bahiensis (Australorbis glabratus), mostrando pela primeira vez um hospedeiro intermediário do trematódio. Tais fatos foram posteriormente confirmados por Leiper e Lutz.
Um dos ancestrais de Pirajá da Silva era o português José Ribeiro da Silva, natural de Vila Nova de Famalicão que veio para o Brasil, na época em que o mesmo se separava de Portugal, e foi residir em Amargosa. Abraçou a causa dos brasileiros por simpatia e incorporou em sinal de inteira solidariedade, um nome indígena aos seus de origem pátria: Pirajá. Nas lutas pela Independência do Brasil, houve batalha pela posse da localidade de Pirajá. Salvador fica em uma península e Pirajá está situada numa elevação na base desta, tendo de um lado as águas do oceano Atlântico e de outro as da Bahia de Todos os Santos. Tem uma posição estratégica em relação à entrada de mantimentos em Salvador, pela Estrada das Boiadas, e domina as enseadas embaixo. José Ribeiro casou-se com Joana Baptista Dantas de Moraes. Do enlace nasceu Maria Veridiana da Silva Pirajá, que se casou com Eduardo Augusto da Silva. Seu primogênito foi Manuel Augusto da Silva, que entrou na Faculdade de Medicina da Bahia em 1891. Matriculado no $1^{\circ}$ ano, mudou seu nome, adotando todo o sobrenome materno e passou a se chamar Manoel Augusto Pirajá da Silva. Teve excelente formação humanística. Quando estudante, aprendeu alemão com o professor Weber e violino com o professor Trautleuf.

Logo depois de formado em medicina, foi atraído pela Amazônia, como aconteceu com outros seus conterrâneos. Mas, após três meses, estava de volta à Bahia.

Em 1908, ele foi para a Europa, levando consigo o abundante material que havia selecionado para suas pesquisas sobre esquistossomose. Fez sua base na Faculdade de Medicina de Paris com o professor Blanchard. Este o apresentou ao professor Lettulle em cujo Serviço completou sua investigação sobre esquistossomose e lhe auxiliou na parte histopatológica. Em Paris, ele fez curso no Instituto Pasteur e no Instituto para Medicina Colonial. Neste, ele obteve uma medalha de Ouro e o título de major, com permissão para praticar medicina nas colônias francesas. Da França, ele foi a Hamburgo, fazendo estágio no Tropeninstitut. Em Hamburgo, ele encontrou Henrique da Rocha Lima que tinha projeção elevada no Instituto, e com quem estreitou sua amizade. Também em Hamburgo, soube por Von Prowazeck da grande descoberta de Carlos Chagas. Ao regressar a Salvador, em Mata de São João, Parafuso e Candeias, encontrou triatomíneos infectados pelo Trypanosoma cruzi, e com Brumpt inocularam camundongos. Assim, tiveram idéia de como a doença havia se alastrado.

Em 1911, ele foi solicitado pelo Comitê que escolheria candidatos ao Prêmio Nobel em 1912 e indicou Carlos Chagas (conforme publicado pelo Jornal de Notícias na Bahia, em 03/02/1913).

O doutor Pirajá da Silva tinha especial pendor para o estudo das doenças tropicais. Antes de tudo era um naturalista. Tinha gosto pelas Ciências Naturais. Em 1902, ele tornou-se assistente de Medicina na Cátedra do Prof. Anísio Circundes de Carvalho. Este tinha voltado de uma visita à França e à Inglaterra, entusiasmado com os Institutos de Medicina Tropical que havia visitado em Paris, Londres e Liverpool, verdadeiras escolas especializadas em Medicina Tropical. 0 Prof. Anísio the aconselhou a se dedicar aos exames laboratoriais para esclarecimento do diagnóstico das doenças tropicais. E assim o fez, montando seu pequeno 
laboratório no Hospital Santa Izabel, em Salvador, Bahia em conexão com a Primeira Cadeira de Medicina Interna.

Ao voltar à Bahia, estudou uma epidemia que grassava em Salvador, chamada de botão de Brotas e verificou que o agente etiológico era a mesma leishmania que produzia a chamada úlcera de Bauru. Antes, já havia se interessado por uma epidemia de meningite cérebro-espinhal epidêmica e pela sífilis. Estudou também casos de amebíase, miíases, ofidismo, casos de paracoccidioidomicose, pé de madura e uma epidemia causada pelo inseto caustico e vesicante conhecido por potó (Paederus columbimis). Na Bahia, em 1911, fez estudos também sobre o Phlebotomus intermedius.

Depois de assumir a cátedra de Parasitologia na Faculdade de Medicina da Bahia, em 1911, Pirajá pela segunda vez voltou a freqüentar o Laboratório de Blanchard em Paris. Também cursou de novo o Tropeninstitut de Hamburgo.

Após tratar das pesquisas sobre a esquistossomose, principal objetivo desta reunião, seria de interesse, em nossa apresentação, falar um pouco sobre o principal protagonista desta noite: 0 doutor Pirajá da Silva. Inclusive para completar as informações sobre sua formação, atividades médicas, e assuntos correlatos, como professor e cidadão. Ele gostava de seu país, de sua gente e da sua Faculdade de Medicina da Bahia. Era um patriota. Reimprimiu às suas custas a publicação do major-cirurgião Bernardino Ferreira da Nóbrega Memória Histórica sobre as Vitórias alcançadas pelos Itaparicanos quando o Brasil Proclamou a sua Independência.

Quando tomou conhecimento da obra de Carlos Frederico Philippe Von Martius, sobre Natureza, Doenças, Medicina e Remédios dos Índios Brasileiros, Pirajá achou que o livro não teve a devida repercussão. Von Martius era etnógrafo e famoso naturalista. Decidiu comentar o livro e com o auxílio de Paul Wolf fazer a tradução do alemão para o português.

Trabalho muito maior teve Pirajá com os comentários sobre o livro Notícias do Brasil, escrito por Gabriel Soares de Sousa, em 1587. Este era um português, senhor de engenho no Jaguaribe e Jequiriçá. Segundo Pandiá Calógeras, o livro de Gabriel Soares é uma das mais notáveis obras da mentalidade portuguesa no século XVI. Trata a um tempo, em relação ao Brasil, de geografia, bistória, topografia, hidrografia, agricultura, borticultura, matéria médica indígena, das madeiras de construção e marcenaria, da zoologia em todos os seus ramos, de economia administrativa e até de mineralogia. Gabriel Soares descreveu magistralmente toda a flora e fauna brasilera. Pirajá da Silva identificou, cientificamente, as magistrais descrições de Gabriel
Soares, de acorso com o sistema de nomenclatura de Lineu. Todos os acidentes topográficos e a etnologia foram interpretados e localizados. A velha toponomia foi comparada com a atual. As anotações de Pirajá são mais extensas do que o texto do livro.

Eu não convivi com Pirajá. Quando cheguei à Bahia, ele já não mais vivia aqui. Mas seus trabalhos foram fonte de inspiração e de estímulo para todos nós e suas pesquisas seguiram nossa melhor tradição de estudar nossas endemias no ambiente onde existiam. Participei de uma reunião em São Paulo, com 35 pesquisadores em 1952, na qual ele compareceu, como homenageado.

Pirajá da Silva teve dois biógrafos, ambos médicos: Itazil Benício dos Santos e Edgard de Cerqueira Falcão.

Edgard de Cerqueira Falcão foi aluno de Pirajá, o admirava muito e tornou-se seu amigo desde 1925. Republicou quase todos os trabalhos de Pirajá e sempre se empenhou no reconhecimento de suas realizações, pois acreditava que não lhe era dado o devido crédito. Achava-o trabalhador, honesto, modesto, grande pesquisador e que via as coisas sem interesse material.

Pirajá e Falcão tinham interesse comum na divulgação de obras de importância relacionadas a assuntos históricos e artísticos, principalmente quando envolvia a Bahia, terra natal de ambos. Geralmente eram documentos de difícil acesso.

Falcão publicou vários livros e, em muitos deles, teve a cooperação de Pirajá, que lhe fornecia documentos antigos e importantes, fazendo traduções e escrevendo comentários. Destes é muito famosa a coleção Brasiliensia Documenta. Falcão publicou, entre outras obras, a reedição do poema épico Paraguassu, de autoria de Ladislau dos Santos Titara; Relação da Conquista e Perda da Cidade de Salvador pelos Holandeses em 1624 - 1625, feita por Aldenburgk, simples soldado que assistiu e tomou parte na campanha; Aprisionamento da Frota de Prata na baía de Matanzas, em Cuba, em 1628, pelo almirante Pieter Heyn; Estudo Crítico dos Trabalhos de Marcgrave e Piso sobre a História Natural do Brasil, à luz dos desenhos originais, de Martin Heinrich Karl Linchtenstein; Zoobiblion _ Livro de Animais de Zacharias Wagener; Plantas Medicinais do Brasil, de Bernardino Antonio Gomes; Notícias do Brasil, de Gabriel Soares de Souza.

Por fim, eu desejo mencionar minha satisfação e honra por estar no meio de ilustres colegas e caros amigos, aqui na nossa querida Bahia, para homenagear um dos seus filhos mais eminente. Quero também expressar meus sinceros agradecimentos pela honra de ter sido escolhido pelos meus companheiros para fazer esta apresentação. 